\title{
BIBLIOTECA INDIANA
}

Publicaciones del Centro de Estudios Indianos/Proyectos Estudios Indianos-PEI

Universidad de Navarra

Universidad del Pacífico (Perú)

Editorial Iberoamericana

Dirección: Ignacio Arellano, Celsa Carmen García y Martina Vinatea

Subdirector: Juan M. Escudero

Coordinador: Elio Vélez

Comité asesor:

Trinidad Barrera, Universidad de Sevilla

Miguel Donoso, Universidad de los Andes, Santiago de Chile

Andrés Eichmann, Academia Boliviana de la Lengua

Paul Firbas, Stony Brook University, The State University of New York

Pedro Lasarte, Boston University

Raúl Marrero-Fente, University of Minnesota, Minneapolis

Alfredo Matus, Academia Chilena de la Lengua, Santiago de Chile

Rosa Perelmuter, University of North Carolina at Chapel Hill

Sara Poot-Herrera, University of California, Santa Barbara

José Antonio Rodríguez Garrido, Pontificia Universidad Católica del Perú, Lima

Biblioteca Indiana, 47 


\section{EL SÍMBOLO CATÓLICO INDIANO (1598) DE LUIS JERÓNIMO DE ORÉ}

Saberes coloniales $y$ los problemas de la evangelización en la región andina

CATALINA ANDRANGO-WALKER

Iberoamericana - Vervuert 
Cualquier forma de reproducción, distribución, comunicación pública o transformación de esta obra solo puede ser realizada con la autorización de sus titulares, salvo excepción prevista por la ley. Diríjase a CEDRO (Centro Español de Derechos Reprográficos) si necesita fotocopiar o escanear algún fragmento de esta obra (www.conlicencia.com; 917021970 / $932720447)$

Derechos reservados

(C) Iberoamericana, 2018

Amor de Dios, 1 - E-28014 Madrid

Tel.: +34 914293522 - Fax: +34 914295397

(C) Vervuert, 2018

Elisabethenstr. 3-9 - D-60594 Frankfurt am Main

Tel.: +49695974617 - Fax: +49695978743

info@iberoamericanalibros.com

www.iberoamericana-vervuert.es

ISBN 978-84-16922-90-1 (Iberoamericana)

ISBN 978-3-95487-744-7 (Vervuert)

ISBN 978-3-95487-745-4 (e-book)

Diseño de la serie: Ignacio Arellano y Juan Manuel Escudero

Imagen de la cubierta:Virgen María, primera edición de Symbolo catholico indiano, Lima, por Antonio Ricardo, 1598.

Diseño de la cubierta: Marcela López Parada 
A John y a Crix 
